\title{
I Feel Good at School! Reducing School Discomfort Levels through integrated Interventions
}

\author{
By Batini Federico ${ }^{*}$,Marco Bartoluccit \& \\ Ermelinda De Carlo
}

\begin{abstract}
Early school leaving is a real social emergency across Europe. Literature and field experience show that the factors leading to the decision to drop out of school are different: family problems, economic distress, territorial discomfort. In addition, there are individual characteristics such as: psychological dimensions, ease/difficulty of learning, ability/disability that may contribute to the rejection and to the school resistance, generating perception of inadequacy and failure. The school, in the short term, cannot affect in a profound way on non-school factors, but it can provide a positive atmosphere at school, allowing children to grow up in a serene environment, where relationships are proposing and stimulating. Aiming to make students feel comfortable at school is a way to diminish their risk to drop out. In this way, "going to school" becomes a choice "to feel well" and not a compulsory requirement. The NoOut project, which is presented here, was created with the main objective to model interventions for recovery and development, to be held during school hours, designed to prevent school dropout from primary school. The actions combine synergistically a teaching of basic skills, guidance, reading aloud (teaching of skills, direct experience, deployment of stimulating and engaging learning environments, personal narratives, narrative guidance paths, narrative training, and educational gaming). This article analyses the results outlined through the TVD test (discomfort evaluation test), which presents a drop on test outcome (that means reduction of risk of school dropout) for the first cycle of education in the first year of the NoOut project. The TVD is a tool that can provide a representation of the perceived school discomfort levels at individual and group level.
\end{abstract}

Keywords: active learning, early school leaving, drop-out, discomfort, distress perceived.

\section{Introduction}

The human being lives within a network of relationships. The type and quality of relationships affect the functioning of the person himself and the methods of learning which will be able to put in place. This may mean that a situation of distress at school is not to be considered an exclusive problem of the student, but a difficult condition that involves all the players in the system of which the boy is part (Batini \& Benvenuto, 2016). The family distress, the

*Professor, University of Perugia, Italy.

†Postdoctoral Researcher, University of Perugia, Italy.

${ }^{\ddagger}$ Postdoctoral Researcher, University of Perugia, Italy. 
economic one and the territorial one represent, for example, external factors that facilitates early school leaving. However, school can intervene appropriately from the inside, avoiding the onset of fatalistic attitudes towards the supposed inevitability of the dispersion for those coming from certain contexts, such as socio-cultural disadvantages, suburbs, poor cultural context etc (Batini \& Bartolucci, 2016).

The aim of this paper is to document research actions and results of an action research project we implemented in an Italian region (Tuscany), with a percentage of early school leavers between $17.6 \%-18.6 \%$ against an EU average of $12.8 \%$, and involved 5 Educational Institutions and 4 training agencies between Arezzo and Florence.

The project called NoOut, of which the Ente Cassa di Risparmio di Firenze is the leader and funder in collaboration with the University of Perugia, ISFOL and Pratika Nausika associations of Arezzo, has set itself the goal of understanding the causes of school dropouts in order to model tools and intervention actions. Areas of research-action focus is both on skills levels and on the levels of well-being at school. The two areas, inevitably and strongly interrelated, foresaw systemic actions. The No Out project was born in order to promote the educational success for all, attaching great importance to the activation, to the leadership and to the welfare of students in school, posing as intervention actions - in addition to the development, rehabilitation and consolidation of basic skills - a narrative approach paths training and reading aloud that facilitate a functional emotional climate activation of the learning group. All this in the awareness of the complexity of the problem and in the need for complex answers (the project also included the training of teachers, educational consulting actions for teachers of experimental classes and meetings with families). "Only if the boy and the problem of his discomfort are considered through a comprehensive approach you can capture the complexity with which it is certainly structured the problem. Conversely, focusing on one factor, such as the socio-cultural one, rather than on those relating to the educational institution, or on the individual or family ones, seemed like an operation strongly marked by reductionist values. [...] Removing a problem or an organisation into its parts may not give us the idea of how it works and of its identity. The fact that the sum of the parts is different from the whole is an idea that, borrowed from the first cybernetics, appeared to be particularly useful in our work" (Mancini \& Gabrielli, 2012, p.18).

Comparative research in literature, experiences of the teachers at school and interviews with dropouts (Batini, 2014) have revealed new factors with respect to the experience of discomfort training, factors that are strongly related to the decision to drop out of school.

Foreigners are growing among young people most at risk (OECD, 2015). Territorial mobility, residential instability, language problems are relevant factors in determining the educational experience. However, among the profiles of dropout children emerge even young people from families of Italian origin, with no serious economic problems, and often wealthy, but where the parents are not very present and where there are no significant adult references. 
Boys grow up developing a kind of distrust of the adult world, showing a strong anger that causes learning experience rejection and feelings of apathy that determine a passive approach to the educational experience (Batini \& Bartolucci, 2016).

That is how a family hardship becomes relational and then inevitably a school distress. The boys in the class appear unmotivated, manifest rejection, feelings of inadequacy. The decision to drop out of school sometimes seems the only possible solution (Batini, 2014).

The school, however, rather than aggravating the discomfort and size exclusion (Batini \& Benvenuto, 2016), can learn to act on the school climate by promoting active teaching methods, an orientation that points to the wellbeing of the subject and the development of orientation-relational skills, reallife skills.

\section{Literature Review}

Educational failure is a primary cause of early school leaving, together with other factors related to the socio-economic and economic conditions of student families, which may aggravate the situation (Sabates, Akyeampong, Westbrook, \& Hunt, 2010). The consequences of a high dropout rate can be tragic in terms of individual, social, family and community costs (Save the Children, 2017). In particular, young people who leave education and training prematurely face more difficulties in the labour market. In the OECD countries, in 2016, the unemployment rate for young people between 25 and 34 years who have not completed upper secondary education is about $17 \%$, compared to $9 \%$ of those who, instead, completed a second-level secondary education path (OECD, 2017). In Europe, the indicator used for the quantification of the phenomenon of early school leaving is that of early leaving form education and training (ELET): young people aged between 18 and 24 with no qualifications or qualifications higher than secondary school and no longer in training. Italy currently ranks in the last places among the 28 European Union countries (after it, only Portugal, Romania, Spain and Malta) with a percentage of ELET equal to $13.8 \%$, against an EU-28 average of $10.7 \%$ (Eurostat, 2017). Although the percentage of ELET is overall decreasing (in 2011 the EU-28 average was $13.4 \%$ and the Italian average of $17.8 \%$, while in 2007 they were respectively $14.9 \%$ and $19.5 \%$ ), our country is still below the target set by the Europe 2020 Strategy, which puts the share of ELET at $10 \%$. A relatively high number of young people between the ages of 18 and 24 continues to be without education qualification after what was termed "middle school". Moreover, among the Italian regions there is a strong variability in the ELET rate: for example, Veneto has already exceeded the European milestone with $8 \%$, while Sicily and Sardinia are at 24\% (Eurostat, 2017). It should be stressed that the ELET indicator provides a measure of the phenomenon of early school leaving and not the current situation, therefore records the outcome of a path when it is too late, preventing, in fact, a preventive intervention or otherwise contrast to the 
phenomenon. To make matters worse, the difficulty of identifying the real number of "missing" is added. In Italy the statistics available at national level often only refer to the formal abandonment (formal request for "renunciation" signed by both parents). So in the last focus on early school leaving (Miur, 2017) there are only the formal dropouts although the term "dispersion" instead of "abandonment" is used, thus underestimating the phenomenon.

School dropout is, in fact, a more complex construct that, strictly speaking, includes students who have formally dropped out of school, those who have not been admitted to the next school year and those who, although enrolled regularly, do not attend classes. In a wider sense, the dispersion also includes the failure to achieve learning and therefore the "dispersion" of the intelligences. By following the narrower definition, it is possible to try to elaborate an estimate of the scholastic dispersion which also includes the slowdowns in the educational path. According to this approach, which takes into account the difference between the number of students enrolled at the beginning of a school cycle and the number of students regularly arriving at its end, in the only fiveyear period of the secondary education system, almost one student out of three is slowed down or stopped by the phenomenon of early school leaving (Batini \& Bartolucci, 2016).

This figure is quite in line with what was found in the latest Education at Glance report (OECD, 2017) which records how - considering OECD countries and partner countries, with available data from studies on real cohorts - the dispersion rate is very high: about $25 \%$ of students enrolled in the upper secondary education cycle did not receive a diploma two years after the end of the regular course of study and four out of five of the same students are no longer enrolled.

Undoubtedly, early school leaving can be taken as an indicator of formative inequality and lack of equity (Benvenuto, 2016) and, more generally, of a lack of quality in the education system in terms of inclusion and educational success (Pandolfi, 2017).

Social peer relations are at the centre of school experience (Pereira \& Pooley, 2007). It is through relationships, new friendships (Akos \& Galassi, 2004), their quality and number, that kids can define their place in a new social hierarchy (Pellegrini \& Bartini, 2000) and increase their sense of self-efficacy and safety (Espelage, Bosworth, \& Simon, 2000), interrelated factors to feel good in different types of schools. Research shows indeed that a positive relational climate improves school performance in terms of learning and participation levels (MacNeil, Prater, \& Busch, 2009; Roeser, Eccles, \& Freedman-Doan, 1999; Vieno, Perkins, Smith, \& Santinello, 2005; Wang, Selman, Dishion, \& Stormshak, 2010; Zullig, Huebner, \& Patton, 2011; Bartolucci \& Batini, 2016), minimizing the risk of discomfort and neglect.

Discomfort, in fact, does not allow the person to experience adequately the activities in the classroom, nor to learn successfully, nor to use the most of their cognitive, affective and relational skills (Mancini \& Gabrielli, 1998).

The school distress manifests itself in different forms now more explicit and obvious now more submerged. It can be detect oppositional attitudes such 
as restlessness, hyperactivity, learning disabilities, attention, difficulties in integrating into the group, lack of motivation, low performance, absenteeism, neglect and even poor frustration tolerance, bullying and arrogance (Pelanda, 1999). On the other hand, it is possible to find attitudes of indifference as the sense of boredom, of discontent, of disinterest. In the latter case generally students do not experience a real school leaving, but a drastic lowering of performance accompanied by low confidence in their own abilities and possibilities (Blum, 2005), in a kind of mutually reinforcing circle between disengagement and poor learning.

The multifactorial nature of distress makes it necessary to read it even in school context in a systemic perspective.

The concept of school climate is closely related to school distress. Acting on the climate means improving the quality of life within the professional community and the community of learners (Cohen \& Smerdon, 2009; Gruenert, 2008).

Zullig, Koopman, Patton and Ubbes (2010) in their research identify among the key components of school climate the way in which they work, within that environment, social relations. It is no coincidence that in the research on the processes of improvement of the school the school climate has an important role (Thapa, Cohen, Guffey, \& Higgins-D’Alessandro, 2013).

A positive school climate promotes the mental emotional social development of the student, facilitates the achievement of positive learning outcomes, ensuring the personal and social acceptance (Loukas \& Robinson, 2004).

A recent study found that the perception of students on school climate could become predictive of attitudes as the victimhood and may make the discomfort at school less tolerable, especially in the transition from primary to secondary school (Hung et al., 2014).

Research by Lester and Cross (2015) have added empirical evidence to the hypothesis that in the transition from primary to secondary school students with a positive perception of school relationships, have higher levels of mental and emotional well-being, and therefore more chance of educational success. The first cycle of education corresponds to a very delicate evolutionary period of a boy growth (Barber \& Olsen, 2004b). The personal, social and family disruption that the boy carries inside himself must find attenuation within school. The greatest risk is an increase in feelings of loneliness, isolation, victimization and negative and even destructive behaviours (Cohen \& Smerdon, 2009; Croce et al., 2009).

Therefore, positive relationships, with teachers and classmates in a primary school may ease the transition to secondary school (Waters, Lester, \& Cross, 2014), reducing the discomfort and anxiety levels (Kuperminc, Leadbeater, \& Blatt, 2001; Ozer \&Weinstein, 2004; Way, Reddy, \& Rhodes, 2007) and antisocial behavior (Frey, Ruchkin, Martin, \& Schwab-Stone, 2009; Kidger, Araya, Donovan, \& Gunnell, 2012).

The scientific literature also shows that peer support enhances the feeling of safety of the school (Cowie \& Oztug, 2008) and reduce bullying (Bartolucci \& Batini, 2016). 
The more a student lives the school and "feels cared forand" by the school (McNeely, Nonnemaker, \& Blum, 2002) greater will be the likelihood of a positive academic performance and active and participatory presence, to build good social relationships and to have increased its mental and emotional wellbeing (Bond et al., 2007).

\section{Methodology}

The intervention sample described in this paper included 80 children in primary schools and 80 secondary school children with their control groups (the totality of the project included also actions of 60 secondary school children of grade II and 75 dropouts). Once the classes and the relative control groups were identified, in the experimental classes a 70-hour training (within the curricular timetable) was carried out, divided into 30 hours of basic skill recovery through authentic tasks and 40 hours of reading aloud with narrative orientation activities. In the control classes the usual didactic activities were carried out (at the same times). The interventions were carried out by counselors and trainers of the Pratika agency in support of the teachers, also with a view in line with the long-term objectives of the project - of disseminating the active teaching methodologies among them. The aim is to compare the developments obtained by students through traditional teaching with those obtained by those who have had the opportunity to take part in an active teaching.

The activities carried out were extended for most of the school year (about 5 months). As a preliminary phase, the teachers of the experimental classes were involved in a micro-planning of the learning units to be implemented, in order to identify, along with the trainers, the activities that could best integrate with the reality and the general level of the individual classes. With regard to the authentic activities proposed, beyond the peculiarity and diversification of contents, it is possible to highlight the following characteristics: for each learning unit, the general objectives have been identified (eg "recovery and strengthening of the basic skills of the Linguistic and Mathematical axis, recovery and enhancement of motivation compared to the study and the school") and the sub-phases and specific objectives for each phase were structured. Each proposed activity involved the realization of an authentic task (eg "creation of a city guide built from the point of view of the participating boys and girls and designed for users of their own age").

Ample space has been given to: individual and group reflection and to the pupils' proposals, also thanks to the use of "narrative stimuli" specially chosen to stimulate discussion on the topics related to the activities to be carried out; constant use of feedback and formative evaluation; space dedicated to selfreflection and self-assessment of the learning achieved during each phase and at the end of the activities (eg use of the logbook, self-assessment tools). In order to verify the effectiveness of experimentation the following instruments were used: the measurement (ex ante and ex post) through questionnaires related to dispersion (TVD), the emotional dimensions (EQ-i: YV) and a cognitive 
test (CAS). In addition, through self-assessment tools (students) and the assessment of teachers it has been possible to verify the learning of students. The project also foresees the longitudinal observation of dropout levels as an additional level of control. In this paper, the attention is focused on the results that was possible to appreciate with regard to evaluations carried out with the TVD tool. The TVD is a test of the discomfort rating and of early school leaving in two parts. The first part consists of 28 stimulus sentences to be completed by the students. This protocol is divided into three main areas: relationship with the self, relationship with the educational institution, relationship with other figures. The analysis of this part is quantitative, it is corrected with the appropriate manual (Mancini \& Gabrielli, 2012) and by using the normative tables. Part B consists of eight stimulus sentences, allowing, crossing the results with those of Part A, a qualitative analysis. The total dimensions investigated by the whole test are five, namely: self-concept, relationship with peers, relationship with the school in general, relationship with teachers, relationship with parents.

Proposals for orient teaching have involved children and teenagers of the first cycle of education (primary and secondary levels) in a vertical curriculum logic. Through routes with guide narration (Batini, 2015), activities and autobiographical play, work has been carried out in small and large groups on identity awareness, the sense of self-efficacy and self-control, imagination, facilitating proactive relationships, stimulants, but above all present and real. Among the objectives of experimentation there was the construction of a positive school climate, in order to offset the discomfort and improve interpersonal skills and self-guidance of children from the earliest years of schooling. The use of the TVD which is a test that helps determine levels of discomfort and dispersion properties, administered ex ante and ex post, has made it possible, initially, to have a starting framework and therefore calibrate and make targeted interventions even within the framework of an overall design.

\section{Findings/Results}

At the end of the path, it was made a comparative analysis of TVD administered pre- and post-experimentation of experimental classes and control classes. The analysis found that students of experimental classes, compared to colleagues in the control classes, had a better perception of themselves and of their abilities from which follows a higher motivation to study and less dispersion (Alivernini \& Lucidi, 2011). For what concern the fourth classes of primary schools the tests did not detect significant changes for both control and experimental groups in line with the provisions of the test which it exerts its best effects, in terms of measurement, in the age range of 12-14 years old. In Figure 1 are shown as an example the results for the primary school involved. 
Figure 1. Graphical Representation of the Results Ex Ante and Ex Post of the TVD in the Primary School of Scandicci (FI)
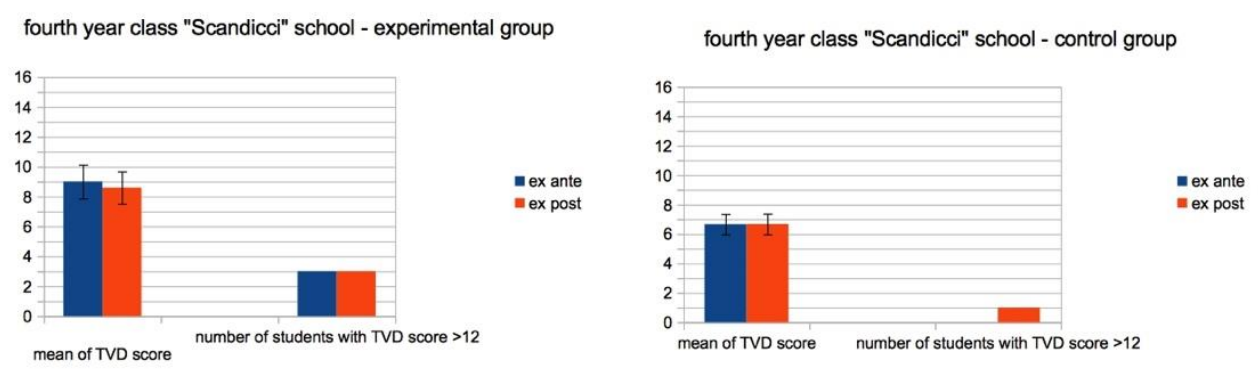

It is clear how there are no deviations in any of the two groups with regard to the average index of individual distress. It is observed in the control group, an increase in the number of individuals who have a score of discomfort that is located on the threshold (12) of the scores that determine concern. Statistically significant results were observed instead with regard to the experimental classes of the two secondary schools who participated in the research and intervention. The trend clearly expresses the lowering of discomfort in all the experimental classes, reaching statistical significance $(F=6.005, p<0.05)$ in the experimental class of third year of Montespertoli. As regards the trend control classes is exactly the opposite indicates an increase in the average score relative to the discomfort felt by the boys reaching statistical significance for the first year classes $(\mathrm{F}=9.407, \mathrm{p}<0.01)$ and third-year class $(\mathrm{F}=18,622, \mathrm{p}$ $<0.001$ ) of the school IV Novembre. We also analysed qualitatively the tests of those guys who had a degree of discomfort with a score greater than 12 (the threshold score for which the test signals a full-blown state of distress). The analysis confirms the above data. Overall, the number of student who reach the danger level rises of a total of four subjects for the control classes while for experimental classes the number is reduced of 10 total units. 
Figure 2. Graphical Representation of the Results Ex Ante and Ex Post of the TVD in the First Grade Secondary School IV Novembre in Arezzo
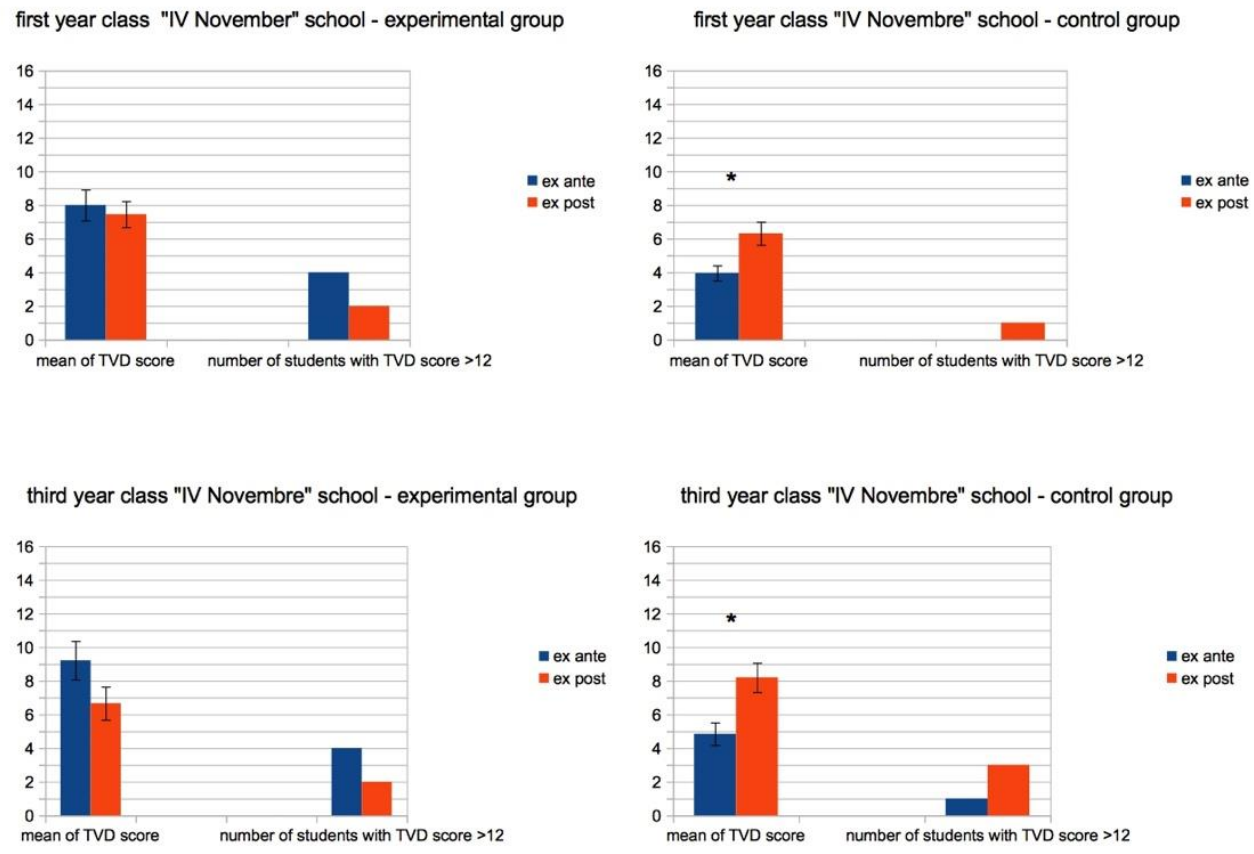

Figure 3. Graphical Representation of the Results Ex Ante and Ex Post of the TVD in the Second Grade Secondary School of Montespertoli (FI)
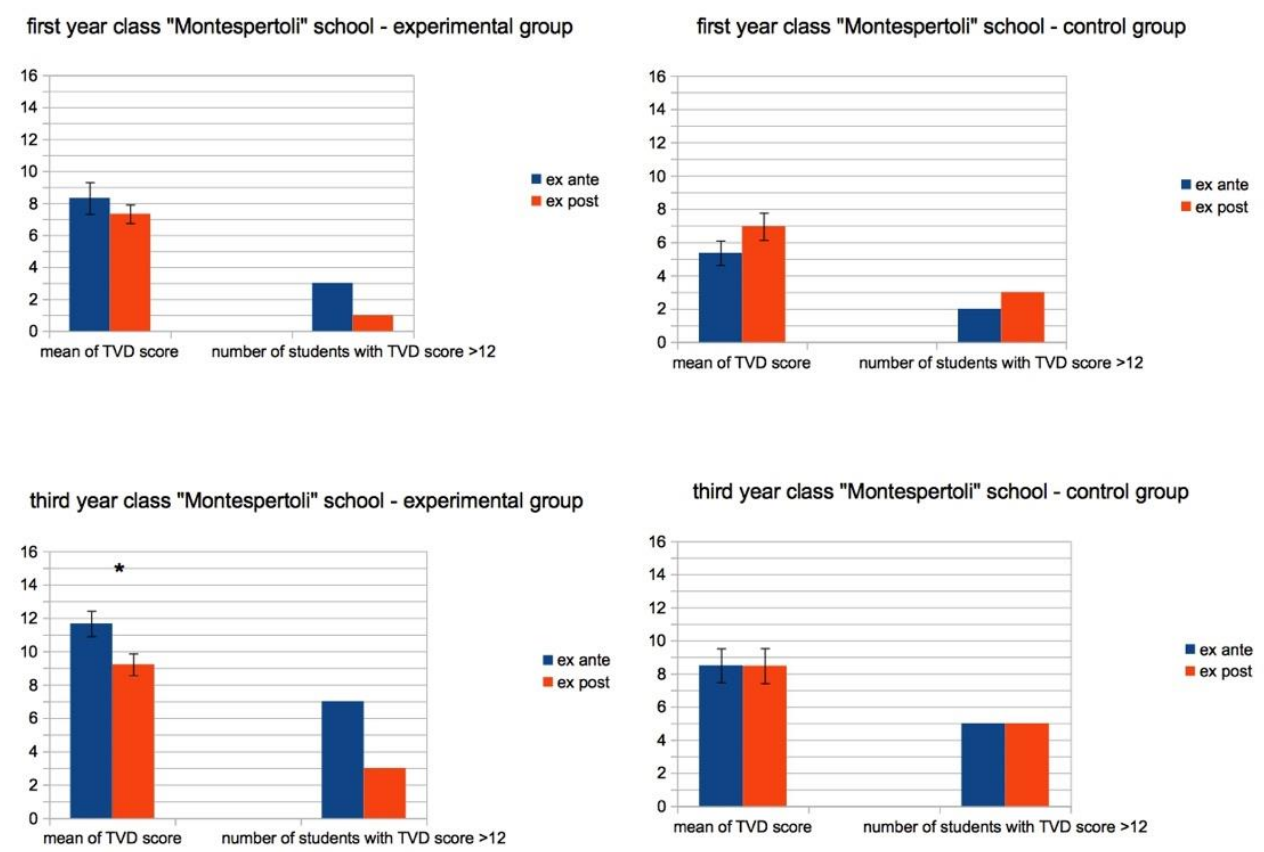


\section{Discussion}

Results show a trend of decrease of distress perceived at school by the experimental classes and, inversely, an increase or stable scores for the control groups. Through active learning and the activities included in the project, students were active and this activation could have improved social relationships between students, and between students and teachers. Attention to the active and central role of the students, together with the presentation, in each meeting, of the activities that would be carried out on that day and the learning objectives they aimed at produced a strong involvement of the students who gradually developed a reflexive attitude about one's own learning. Each student was led not only to express a direct opinion on the activities, but to put in place a real metacognitive exercise that was directly influencing the motivation to continue the activities and to strengthen the learning acquired through them, thus contributing to also strengthen their self-esteem and perceived self-efficacy. Each didactic action was characterized by the activation of the students and the possibility of expressing choices and opinions. The students became an active part in the decision-making process, in the exchange and formalization of the acquired activities and learning. We know form previous research that a positive relational climate improves school performance in terms of learning and participation levels (MacNeil, Prater, \& Busch, 2009; Roeser, Eccles, \& Freedman-Doan, 1999; Vieno, Perkins, Smith, \& Santinello, 2005; Wang, Selman, Dishion, \& Stormshak, 2010; Zullig, Huebner, \& Patton, 2011; Bartolucci \& Batini, 2016), minimizing the risk of discomfort and neglect. Students when are active and working in groups, sharing knowledge and thoughts about activities proposed, may feel a sense of effectiveness, reducing boredom, feelings of loneliness, isolation, victimization, and thus experiencing positive relationships, with teachers and classmates, that leads to facilitation on the achievement of positive learning outcomes, and a general sense of well being in the school context. The distress issue is very important in all school levels, although in primary school is even more important because it could become predictive of bad attitudes, especially in the transition from primary to secondary school (Hung et al., 2014). In this transition in fact, students whom experience mental and emotional well being, are more likely to have chances of educational and social success. Having experienced a good climate in primary school means reducing the discomfort and anxiety levels during the transition to secondary school, and this could lead to a better develop of social interactions, attitudes to learning, and self-confidence in expressing their own personality, beliefs and motivations in the classroom context.

\section{Conclusions}

The elements that determine the success of an experiment are never isolated. In this case the possibility of obtaining extremely positive effects in the trial of the project NoOut feed on a range of sources that reinforce each other. If the TVD data can also be read "backwards", ie showing what 
happened in the control classes, with a situation that was static in the best cases it is also possible to cross the results of the TVD with other instruments used. In fact, the results of the TVD suggest a greater mastery of their learning processes in relation to the Instrument dimensions: self-concept, relationships with peers, with teachers and the school in general, the relationship with parents. This explanatory hypothesis is further confirmed by the individual administering tests CAS outcomes that showed a statistically significant increment for all experimental classes of the sample relative to the first school cycle (Batini, DeCarlo, \& Bartolucci, 2017).

The conclusions that we can draw are therefore related to the effectiveness of the 70 hours of intervention in each class (divided into 20 hours of recovery/ development of basic skills in mathematics area, 20 hours of recovery/ development of basic skills of language area, 10 hours of narrative orientation and 20 hours of reading aloud). Statistically significant data and performance trends allow then to identify in the intervention carried out (the paths on the teaching of skills can be downloaded for free in dispersione.it site) an effective antidote to school distress and the strengthening of cognitive and social tools of the subjects involved. The TVD being a questionnaire where respondents must complete sentences, it is also a very versatile tool for a series of longitudinal surveys in succession. In addition to longitudinally evaluate the influences of various experimental activities in the classroom, it could also allow you to explore qualitatively the answers in order to analyze the nuances of change that could arise from small or medium differences in subjects' responses.

The school can, therefore, achieving wide impact on improving school climate and well-being by promoting learning situations in which students can mobilize skills and potential. This is only possible through an appropriate and specific teacher training.

\section{References}

Alivernini, F., \& Lucidi, F. (2011). Relationship between social context, self- ef cacy, motivation, academic achievement, and intention to drop out of high school: a longitudinal study. The Journal of Educational Research, 104, 241-252

Akos, P., \& Galassi, J. (2004). Middle and high school transitions as viewed by students, parents and teachers. Professional School Counselling, 7(4), 213-221.

Barber, B. K., \& Olsen, J. A. (2004). Assessing the transitions to middle and high school. Journal of Adolescent Research, 19(1), 3-30.

Bartolucci, M., \& Batini, F. (2016). C'era una volta un pezzo di legno [Once upon a time there was a piece of wood]. Milano: FrancoAngeli.

Batini, F. (2015). To Choose or to Plan? The Narrative Orientation as an Answer to the Change of Orientation Need. Pedagogia Oggi, 1/2015.

Batini, F. (2014). Dropout. Arezzo: Fuorionda- Altreducazione.

Batini, F., \& Bartolucci, M., (2016). La dispersione scolastica. Ascoltare i protagonisti per comprenderla e prevenirla [Early school leaving. Listen to the protagonists to understand and prevent it]. Milano: FrancoAngeli.

Batini, F., \& Benvenuto, G. (2016). Le parole disperse. La voce degli studenti drop- 
out e la ricerca etnografica in pedagogia [The word "disperse". Student drop-out voice and ethnographic research in education]. In G. Szpunar, P. Sposetti, A. Sanzo, A. (Eds.), Narrazione e educazione. Roma: Nuova Cultura.

Benvenuto, G. (2016). 1990-2015: Una lunga storia di analisi e progetti di intervento a contrasto della Dispersione Scolastica. Dove abbiamo sbagliato? [ 1990-2015: A long History of analysis and intervention project to combact Early school leaving. Where did we go wrong?]. In F. Batini, \& M. Bartolucci, (Eds), Dispersione scolastica. Ascoltare i protagonisti per comprenderla e prevenirla, (pp. 123-133). Milano: Franco Angeli.

Blum, R. (2005). A case for school connectedness. Educational Leadership, 62(7), $16-20$.

Bond, L., Butler, H., Thomas, L., Carlin, J., Glover, S., Bowes, G., \& Patton, G. (2007). Social and school connectedness in early secondary school as predictors of late teenage substance use, mental health and academic outcomes. Journal of Adolescent Health, 40(4), 9-18.

Cohen, J., \& Smerdon, B. (2009). Tightening the dropout tourniquet: Easing the transition from middle to high school. Preventing School Failure, 53(3), 177184.

Cowie, H., \& Oztug, O. (2008). Pupils' perceptions of safety at school. Pastoral Care in Education: An International Journal of Personal, Social and Emotional Development, 26(2), 59-67.

Espelage, D., Bosworth, K., \& Simon, T. (2000). Examining the social context of bullying behaviors in early adolescence. Journal of Counseling and Development, 78(3), 326-333.

Eurostat (2017). Early leavers from education and training. Retrieved from https://bit.ly/2EzXpFk.

Frey, A., Ruchkin, V., Martin, A., \& Schwab-Stone, M. (2009). Adolescents in transition: school and family characteristics in the development of violent behaviors entering high school. Child Psychiatry and Human Development, 40(1), 113.

Gruenert, S. (2008). School culture, School climate: They are not the same thing. Principal, 87, 56.

Hung, A. H., Luebbe, A. M., \& Flaspohler, P. D. (2014). Measuring School climate: Factor analysis and relations to emotional problems, conduct problems, and victimization in Middle School Students. School Mental Health, 1-15.

Kidger, J., Araya, R., Donovan, J., \& Gunnell, D. (2012). The effect of the school environment on the emotional health of adolescents: A systematic review. Pediatrics, peds. 2011-2248.

Kuperminc, G. P., Leadbeater, B. J., \& Blatt, S. J. (2001). School social climate and individual differences in vulnerability to psychopathology among middle school students. Journal of School Psychology, 39(2), 141-159.

Lester, L., \& Cross, D. (2015). The relationship between school climate and mental and emotional wellbeing over the transition from primary to secondary school. Psychology of Well-BeingTheory, Research and Practice, 5-9.

Loukas, A., \& Robinson, S. (2004). Examining the moderating role of perceived school climate in early adolescent adjustment. Journal of Research on Adolescence, 14(2), 209-233.

MacNeil, A. J., Prater, D. L., \& Busch, S. (2009). The effects of school culture and climate on student achievement. International Journal of Leadership in Education, 12(1), 73-84. 
Mancini, G., \& Gabrielli, G. (2012) (ed. or 1998). TVD Test di valutazione del disagio e della dispersione scolastica [TVD Test Evaluation test of discomfort and early school leaving]. Trento: Erickson.

Miur (2017). La dispersione scolastica nell'a.s. 2015/2016 e nel passaggio all'a.s. 2016/2017 [Early school leaving in SY 2015/2016 and in the transition to SY 2016/2017]. Retrieved from https://bit.ly/2Ezer6v.

OECD (2015). International Migration Outlook 2015. OECD Publishing.

Ozer, E. J., \& Weinstein, R. S. (2004). Urban adolescents' exposure to community violence: The role of support, school safety, and social constraints in a schoolbased sample of boys and girls. Journal of Clinical Child and Adolescent Psychology, 33(3), 463-476.

Pelanda, E. (1999). Il dolore psichico: una chiave di lettura dell'abbandono scolastico [Psychic pain: a key to reading off school leaving]. In O. L. Sempio, E. Confalonieri, G. Scaratti. L'abbandono scolastico. Aspetti culturali, cognitivi, affettivi. Milano: Raffaello Cortina.

Pellegrini, A., \& Bartini, M. (2000). A longitudinal study of bullying, victimization, and peer affiliation during the transition from primary school to middle school. American Educational Research Journal, 37(3), 699-725.

Pereira, A., \& Pooley, J. (2007). A qualitative exploration of the transition experience of students from a high school to a senior high school in rural Western Australia. Australian Journal of Education, 51(2), 162-177.

Sabates, R., Westbrook, J., Akyeampong, K., \& Hunt, F. (2010). School drop out: Patterns, causes, changes and policies. United Kingdom: University of Sussex

Save the Children. (2017). Futuro in partenza? L'impatto delle povertà educative in Italia [Future at the start? The impact of educational poverty in Italy]. Retrieved from https://bit.ly/2nIYSWc.

Thapa, A., Cohen, J., Guffey, S., \& Higgins-D'Alessandro, A. (2013). A review of school climate research. Review of Educational Research, 83(3), 357-385.

Vieno, A., Perkins, D., Smith, T., \& Santinello, M. (2005). Democratic school climate and sense of community in school: A multilevel analysis. American Journal of Community Psychology, 36, 327-341.

Wang, M. T., Selman, R. L., Dishion, T. J., \& Stormshak, E. A. (2010). A tobit regression analysis of the covariation between middle school students' perceived school climate and behavioral problems. Journal of Research on Adolescence, 20(2), 274-286.

Waters, S., Lester, L., \& Cross, D. (2014). Transition from primary to secondary school: Expectation vs experience. Australian Journal of Education, 58(2), 153166

Way, N., Reddy, R., \& Rhodes, J. (2007). Students' perceptions of school climate during the middle school years: Associations with trajectories of psychological and behavioral adjustment. American Journal of Community Psychology, 40(34), 194-213.

Zullig, K. J., Huebner, E. S., \& Patton, J. M. (2011). Relationships among school climate domains and school satisfaction. Psychology in the Schools, 48(2), 133145.

Zullig, K. J., Koopman, T. M., Patton, J. M., \& Ubbes, V. A. (2010). School climate: Historical review, instrument development, and school assessment. Journal of Psychoeducational Assessment, 28(2), 139-152. 
